\title{
Gottlieb Burckhardt and Egas Moniz - Two Beginnings of Psychosurgery
}

Zbigniew Kotowicz*

\section{Summary}

This article compares the repercussions of the two attempts at psychosurgery, the first in 1888 by the Swiss psychiatrist Gottlieb Burckhardt and the second by the Portuguese neurologist Egas Moniz. Both widely publicised their procedure, yet, Burckhardt was condemned and no one ventured to repeat his operation, whereas Moniz's leucotomy was accepted and it soon entered mainstream psychiatry. The change of Zeitgeist does not explain the difference as the thinking in the time of Burckhardt, dominated by Griesinger's 'mental illness is an illness of the brain' doctrine, would appear to be more favourable to psychosurgery than it was in the time of Moniz. Moniz reported far more favourable results, which no doubt impressed other practitioners. But most of all the adoption of psychosurgery was due to the interest in mental illness of nonpsychiatrists - neurologists and neurosurgeons -, and the arrival of the new treatment marks a change in the professional configuration of those who treat psychiatric afflictions. This article deals with the early adoption of psychosurgery. Further developments, such as the relation of psychosurgery to other treatments and the fall into disrepute of the technique, are outside the scope of this presentation ${ }^{1}$.

Keywords: Egas Moniz; Gottlieb Burckhardt; experimental neuropsychiatry; neural circuits; psychosurgery

\footnotetext{
* Zbigniew Kotowicz is Wellcome Research Fellow in the History of Medicine at the Department of History, Goldsmiths College, University of London.

1 These matters have been looked at comprehensively by such scholars as Eliot Valenstein (1980 and 1986), Jack Pressman (1998) and Joel Braslow (1997).
}

Zbigniew Kotowicz, Department of History, Goldsmiths College, University of London, New Cross, UK-London SE14 6NW (z.kotowicz@gold.ac.uk). 


\section{Introduction}

In 1936 a monograph Tentatives opératoires dans le traitement de certains psychoses appeared. It was brought out by the reputed Parisian medical publisher Masson and was authored by the Portuguese neurologist Egas Moniz (1874-1955). In this work Moniz announced a new treatment for the mentally ill. It was a surgical intervention, which directly targeted the brain. He named the procedure prefrontal leucotomy and coined the term psychosurgery. In 1949 this new technique earned him the Nobel Prize in Physiology and Medicine ${ }^{2}$, which confirmed the beginning of an era of direct brain intervention as a psychiatric remedy. However, a number of accounts of the history of psychosurgery begin with an attempt carried out by the Swiss psychiatrist Gottlieb Burckhardt (1836-1907) as early as 1888. He published a long detailed report of his work in a paper 'Ueber Rindenexcisionen, als Beitrag zur operativen Therapie der Psychosen' in a Berlin periodical Allgemeine Zeitschrift für Psychiatrie und psychischgerichtliche Medizin in $1891^{3}$.

It should be noted that it is not the case, as sometimes happens, that Burckhardt was forgotten, only to be discovered some time later and subsequently restored to his rightful place in history. His surgical interventions were periodically commented on in literature. The Russian neurologist Vladimir Bechterev and his Estonian colleague the neurosurgeon Ludvig Puusepp brought the matter up in a paper in 1912, Puusepp again in 1937; the Italian Emilio Rizzatti in 1937; the Americans Walter Freeman and James Watts in 1942, the Portuguese psychiatrist Almeida Amaral in 1945 and the doyen of American neurology, John Fulton, in 1951. So whether to begin the story of psychosurgery with the earlier Burckhardt or the later Moniz is a matter of choice ${ }^{4}$. Generally speaking, one could say that the medical community tends to place the beginning of the practice of psychosurgery with Moniz ${ }^{5}$, whereas

2 The prize was split, with the other half going to the Swiss physiologist Walter Hess for his discovery of the functional organisation of the interbrain as a coordinator of the activities of the internal organs.

3 Those who do not read German with ease (which includes the author) can consult Whitaker/ Stemmer/Joanette (1996) 'A Psychosurgical Chapter in the Cerebral Localisation: The Six Cases of Gottlieb Burckhardt (1891)', in: Code, C. et al. (eds), Classic Cases in Neuropsychology, which is a summary of Burckhardt's paper with large chunks of the original translated. There are also other good accounts (Berrios 1997, Stone 2001 and Joanette et al. 1993) that fill out the story.

4 Various late-nineteenth-century attempts at surgery by Shaw and others were genuinely forgotten and only unearthed recently (Berrios 1997), which is why they are not discussed in this paper.

5 'The surgical treatment of psychiatric disease was introduced by Moniz in 1936 and soon became widely accepted and commonly practised throughout the world', begins one recent communication on psychosurgery (Splangler et al. 1996). 
historians of medicine are inclined to begin with Burckhardt, though there are exceptions ${ }^{6}$. It would seem that to the practitioners the history proper of a treatment begins not with the actual first attempt, but at the moment it is put on the medical map, when it turns into a shared practice. Freeman and Watts dedicated their monograph Psychosurgery 'To Egas Moniz, who first conceived and executed a valid operation for mental disease' (Freeman and Watts 1942). This pretty much sums up the feelings of most of the medical community. Interestingly, those hostile to psychosurgery also tend to begin with Moniz (Sacks 1995), or reserve for him their venom (Valenstein 1986; Shorter 1997) ${ }^{7}$.

However, establishing priority is of little intrinsic interest to historians. What matters a great deal more are the very different ways the medical community received the work of Burckhardt and of Moniz. Burckhardt was condemned outright, whereas Moniz's work was greeted by many with enthusiasm and psychosurgery spread rapidly; at one point it was thought to be the ultimate answer for psychiatry. Was it that Moniz was better than Burckhardt at convincing his peers that psychosurgery was a valid approach, was it that the professional milieu of Moniz's time was more receptive to such an idea than it was in the time of Burckhardt, or was it that Moniz's attempt was inherently more convincing? As might be expected, the answer to this is not simple. A number of different factors were in play and a comprehensive understanding of these should lead to a better appreciation not only of the place of psychosurgery in psychiatric practice but also of a wider range of questions concerning the history of psychiatry.

\section{The two psychosurgery attempts}

Gottlieb Burckhardt trained as a physician and, after working for a time as a general practitioner, took up a post at the psychiatric university clinic in Berne. In his earlier days Burckhardt was very active and a number of scientific publications came from him. These included, amongst others, studies on sensory aphasia and on functional centres of the brain and their relation to psychiatry and neurology (Stone 2001, 80f.). Between 1881 and 1896 he was in charge of a small asylum at Préfargier, near the Lake of Neuchâtel; he was what was then called an alienist. It was there in 1888 and 1889 that Burckhardt, who had no formal training in surgery, operated on the brains of

6 Jack Pressman (Pressman 1998) does not mention Burckhardt at all.

7 Edward Shorter, in fact, is not hostile in principle to psychosurgery, but for Moniz he clearly has contempt (Shorter 1997, 226f.). 
six patients. The following year he presented results of his work at the widely attended Berlin Medical Congress. The response was not encouraging, 'his presentation caused a chill in the room' (Joanette et al. 1993), and the mood was that it would be best to bury the idea of psychosurgery straightaway. Kraepelin later remarked that Burckhardt 'suggested that restless patients could be pacified by scratching away the cerebral cortex' (Berrios 1991,186). Undaunted, Burckhardt published a report of his work. He presented detailed case histories, and he comprehensively reviewed the current literature to give theoretical support to his new approach. The monograph is of great quality and one would have thought that it would at least have provoked a debate; but the response was poor and Burckhardt was forced to abandon his work $^{8}$. Soon the matter was as good as forgotten. Some twenty years later Bechterev and Puusepp discussed the issue again and condemned Burckhardt in harsh and uncompromising terms. They wondered how anyone holding a medical diploma could undertake such folly (Bechterev/Puusepp 1912, 84). What the authors did not say was that one of them (Puusepp) had actually attempted brain surgery on three mentally ill patients two years earlier. The results were very discouraging and it seems that it was this experience that prompted the attack on Burckhardt.

The next publicised attempt at psychosurgery took place in 1935 in Hospital Santa Marta in Lisbon. The procedure was devised by Egas Moniz. Moniz was one of the leading neurologists of his generation, and his major achievement was to develop a method of obtaining X-ray images of the blood circulation of the brain. In his first monograph Moniz called the technique arterial encephalography (Moniz 1931) and in the second, cerebral angiography (Moniz 1934), which is what it became known as. Angiography was a dominant theme in Moniz's scientific career. He worked on improving the technique to the end of his career; publishing in addition to the two monographs about 200 articles on various aspects of it. It is the basis for the angiographic techniques still in use today and, together with Berger's electroencephalogram and Dandy's ventriculography, it belongs in the lineage of great advances in diagnostic techniques that pushed the frontiers of neurosurgery; it was also of immense value in research. Moniz was twice nominated for the Nobel Prize for it.

Prefrontal leucotomy, the brain surgery for the mentally ill, was devised ten years later. The operation was carried out under the direction of Moniz by Pedro Almeida Lima, a skilled neurosurgeon whose training included a

8 Burckhardt continued as director of the Préfargier asylum and later was director of the Sonnenhalde mental hospital near Basel; but his scientific career seems to have come to an end as his publications dried up. 
spell with Sir Hugh Cairns in London. (Moniz could not operate himself because he was not a trained surgeon and in addition his hands were deformed by gout so there was no question of learning to carry out the relatively easy technique himself, as Burckhardt did.) Between November 1935 and February 1936 they operated on twenty patients'.

Just like Burckhardt before him, Moniz was keen to share the results with his colleagues and published a number of reports of his work, as well as the monograph. The following year his young assistant Diogo Furtado went to Paris and presented results from a second batch of patients, twenty-one of them. The presentation took place at a meeting of the Société Médico-Psychologique in Paris on 26th July 1936. Moniz must have had high hopes, as Paris was the scene of his earlier scientific triumph; almost exactly a decade earlier he had presented there, to much acclaim, the results of the first successful angiograms. However, in 1936 there was to be no repeat of the earlier triumph; the reception was just as cold and hostile as the one that Burckhardt had met in Berlin almost 50 years earlier.

Up to this point the story is quite similar to Burckhardt's, both were met with hostile response, but subsequent developments were very different. While the hostility of his colleagues forced Burckhardt to abandon the procedure, within a year of the publication of the monograph Moniz's operation was taken up enthusiastically in Italy and was also repeated in Romania, Brazil and the United States. The forties saw an intense growth in the numbers of patients operated on. The First International Psychosurgery Congress that was held in Lisbon in 1948 attracted delegates from 26 countries. Reports included operations on chronic patients as well as acute, schizophrenics and manic-depressives, old patients as well as children. The following year Moniz was awarded the Nobel Prize ${ }^{10}$.

9 The first seven operations consisted of injections of absolute alcohol into the frontal lobes, six on each side, with the aim of creating a 'frontal barrier'. Not quite satisfied with the results, Moniz decided to severe the connections surgically. To this end he had made for him by Parisian medical instrument makers a leucotome, an instrument, which was a plunger-activated corer. It was inserted through the trepanned holes, through the cortex into the white matter. Then through pressing the top end a wire loop was extruded with which, by turning around the leucotome, cuts were made. The eighth and ninth patient were operated with it. The following three had alcohol injections. The last eight (from 13th to 20th) were leucotomised. In his discussion of the cases Moniz does not differentiate between them and treats them as a uniform batch.

10 Although the Congress attracted a truly international turnout, this should not obscure the fact that psychosurgery was taken up in different countries with different degrees of enthusiasm. Overall, the vast majority of psychosurgery was performed in the United States and Britain. But the first to embrace the technique were the Italians. Within two years they reported on hundreds of cases (Rizzatti 1938) and already carried out comparative studies between psychosurgery and other shock treatments (Torsegno 1938). The outbreak of war 


\section{Zeitgeist}

It has been noted that the reasons for such divergent reactions to the work of Burckhardt and Moniz have not been fully understood (Berrios 1997). One argument that has been frequently advanced is that the success of psychosurgery was due to the immense interest in the technique in the United States. However, the fact that the operation was repeated in a number of different countries so quickly, as well as the truly international character of the first Congress, indicates that this cannot be a complete explanation. There is, though, no doubt that when in 1942 Freeman and Watts brought out their monograph Psychosurgery, a far superior work to Moniz's hastily prepared report, the American influence began to count for a great deal indeed ${ }^{11}$. Moniz, incidentally, recognised the importance of the developments that took place across the Atlantic and at the time of the Lisbon Congress talked of psychosurgery as a 'Luso-American' procedure (Moniz 1949b, 21).

Another explanation for the different receptions accorded to Burckhardt and Moniz is that the Zeitgeist had changed. This must be true, only that, strangely, when we look at the scientific thinking in the time of Burckhardt, it appears to be more favourable to psychosurgery than it was in the time of Moniz.

In the second half of the nineteenth century there was no clear distinction between psychiatrists and neurologists. Hospital wards housed both neurological and psychiatric patients and consequently the medics who worked on those wards were usually both neurologists and psychiatrists. The likes of Jean Martin Charcot in Paris, or Theodor Meynert and Karl Wernicke in Germany, are prominent figures both in histories of psychiatry and neurology. Some were clinicians as well as researchers, others, particularly the Germans, based in university clinics that were separate from the asylums, tended to work less with their patient population and instead spent long hours hunched over microscopes scouring brain tissue in search of signs of mental illness. But

\footnotetext{
brought to an end these activities. The German psychiatrists, on the other hand, seemed at first not to want to have anything to do with; there was no representative from Germany at the Lisbon Congress. In the fifties the technique was taken up, though on a limited scale. The Neurosurgical Clinic of the University of Freiburg was one of the centres of activity (Riechert 1977). Judging from the rarity with which German titles turn up in numerous bibliographies on psychosurgery, the technique could not have been ever widely accepted. In the Soviet Union psychosurgery was banned. What general lessons about psychosurgery as such could be drawn from this brief overview is not clear, but it needs signalling as how psychosurgery was received in different countries might throw some light on the state of psychiatry in the respective countries at the time.

11 In England, for example, only seven leucotomies were performed before 1942, by 1950 some 10,000 were already performed.
} 
whatever the differences in working practices, and whether it was France, Germany or England, the prevailing approach was to apply the neurological method into the psychiatric domain, and the conviction that mental illness has an anatomical base was widely held. This was the environment in which Burckhardt worked.

Meynert and Wernicke made very important contributions to neurology but in psychiatric matters they drew a blank. Clinicians were coming to terms with the fact that there were vast numbers of hospital inmates who appeared to be afflicted by mental malfunctioning, but no cerebral pathology could be detected. As a consequence, early in the twentieth century, a clear distinction between neurology and psychiatry had been worked out. Mental illnesses were classified into two basic groups, dementia praecox (later renamed schizophrenia) and manic-depressive psychoses. Karl Kahlbaum, Emil Kraepelin and Eugen Bleuler are the principle psychiatrists responsible for the new classification. At the same time, a whole array of disturbances of speech, memory and motor functioning were recognised as being of a neurological nature, meaning that they could be related to specific cerebral processes; a number of specific illnesses such as Alzheimer's or Parkinson's were described. Paul Broca, John Hughlings Jackson, Alois Alzheimer, Franz Nißl, Joseph Babinski are some of the neurologists associated with these developments.

The outcome of all this work was that the beginning of the century saw a clear division of labour. There remained an overlap in that a psychiatrist was taught to recognise neurological symptoms and a neurologist would be expected to diagnose a mental illness, but otherwise their respective fields became separate. This was reflected in teaching structures as independent Chairs of Neurology and Psychiatry became common ${ }^{12}$. Treatments specifically designed to tackle mental illness also began to be developed. The earlier ideas of moral improvement evolved into more comprehensive psychotherapeutic interventions. Various shock treatments were devised to deal with intractable patients crowding the hospital wards. Some of them had a modicum of success, such as Wagner-Jauregg's malaria treatment of neurosyphilis. He was awarded the Nobel Prize for it in 1926, the first psychiatrist to win the prize. All this must have felt as a vast improvement on the swinging chairs, cold showers, straightjackets, enemas, bloodletting and various other 'treatments' that made up the armamentum of a nineteenth-century alienist.

12 In Moniz's Portugal separate Chairs of Neurology and Psychiatry were set up in 1911 (in Lisbon, Oporto and Coimbra). However, the institutional separation of psychiatry and neurology did not take place everywhere, and in some countries (Holland, for example) it had to wait until the seventies. 
There was also a new theoretical sophistication. The arrival of psychoanalysis and phenomenology influenced to varying degrees psychiatrists such as Eugen Bleuler, Karl Jaspers, Kurt Schneider, Karl Bonhoeffer. They developed an approach that has been termed dynamic psychiatry (Ellenberger 1970). Research into the links between brain anatomy and mental illness declined. Jaspers's attack on Meynert for creating a 'brain mythology' would be quite representative of the psychiatric Zeitgeist in which Moniz operated $^{13}$.

A comparison between Burckhardt's and Moniz's reports bears this out. Burckhardt was much more in tune with the thinking of his time and so he found and quoted quite a number of contemporary alienists and neurologists to support his approach. Moniz, on the other hand, referred at length to neurological findings concerning the functioning of the frontal lobe, particularly the work of the Russian neurologist Choroschko (Choroschko 1935); he commented on findings presented at the International Congress of Neurology that took place in London in $1935^{14}$, but he did not quote any psychiatrists to support his case, although he did elsewhere express praise for the now rarely mentioned Klaus Kleist from Frankfurt who was a faithful (and only) follower of the Wernicke school and attempted to develop a strict localisationist theory ${ }^{15}$.

13 As usual, when we are recounting a general trend, some exceptions can be found. In this case, one such notable exception is Eugen Bleuler. He was one of the first psychiatrists to take psychoanalysis seriously and made much use of it when formulating his concept of schizophrenia. Nevertheless, years later he held firmly that 'schizophrenia has in common with other organic psychoses symptoms that derive directly from cerebral processes' (Bleuler 1926,17), without, however, being able to demonstrate what these processes were.

14 The Congress was attended by the cream of the neurological world. It was there that John Fulton and Carlyle Jacobson presented the two famous lobotomised chimpanzees Becky and Lucy. Much was made of the fact that Moniz did not mention these experiments as influencing his decision to go ahead with psychosurgery; but Moniz had no need to mention the chimpanzees. He was particularly (and more logically) impressed with the case presented and discussed at some length by Richard Brickner. It was a case of a patient who had his frontal lobes ablated to relieve meningioma. What attracted Moniz's attention was that the man suffered some flattening of affect but retained all his intellectual capacities (Moniz 1936a,35-38). (By the time of the London Congress Brickner had already published a lengthy account of the case [Brickner 1932] and later went on to publish a full monograph [Brickner 1936].)

15 Kleist's localisation of functions in the cerebral cortex is almost as fanciful and exotic as the early phrenological cartographies. He is better remembered, however, for being part of the Wernicke-Kleist-Leonhard school, which is best known for its concept of cycloid psychoses (Beckmann/Franzek 1999; Perris 1995; Neumärker/Bartsch 2003). 


\section{Results}

However, whatever the Zeitgeist, what all men and women of medicine look at first are results, and in this respect Moniz's report was far more impressive than Burckhardt's. Burckhardt operated on six patients. He declared improvement in four cases, but one of the patients died, another was found drowned three weeks after discharge from hospital; postoperational complications included epileptic seizures. Burckhardt thought this outcome was encouraging, but it is difficult to share his assessment. Moniz operated on 20 patients and reported no fatalities. The postoperation complications that he reported were milder (confusion, incontinence) and tended to be transitory. There was no occurrence of epileptic seizures.

There was also a difference in what they aspired to achieve. Burckhardt quite openly stated that he hoped to turn violent unmanageable patients into manageable patients. Before the operation they were deluded, hallucinated and were violent. After the operation they were different, " $[\mathrm{t}]$ he patient had changed from a dangerous and excited demented person to a calm demented one' (Whitaker et al. 1996, 279). Or another case, '[t]he plainly visible result of the operation is that the patient has been altered from a disagreeable, occasionally violent patient, dangerous to his comrades, into a harmless working patient inhabiting the quiet ward. Demented he remains' (Whitaker et al. 1996, 291f.). Moniz, on the other hand, talked of treatment and cure. Of the 20 patients he declared a third greatly improved, a third mildly improved and no change was observed in the last third. Moniz also included photographs of some of the patients, in some cases taken before and after the operation to show how different they were. He says he does not attach much importance to them but evidently a little photographic documentary leaves an additional impression ${ }^{16}$. However, the critical factor must have been that Moniz demonstrated that the operation, if performed carefully, should not endanger life. And indeed, there was enough material from the neurological clinic to suggest that the lack of fatalities reported by Moniz was no lucky accident.

These results were difficult to ignore. One early reviewer of Moniz's monograph expressed doubts about the theoretical grounding of the procedure, thought it to be a 'demolishing surgery' and pointed out that 'every anatomical loss always diminishes the functioning of the whole organ' (Gozzano 1937, 92), but all the same, he noted that 'considering the treatment from a

16 This, it would seem, is a new development in the iconography of the insane. While earlier textbooks would often dwell on striking physiognomy to depict the mad, here we have the before and after treatment pictures, akin to plastic surgery case presentations. 
purely practical point of view it is undeniable that the results obtained are quite satisfying' (Gozzano 1937, 91). And he was not alone. The anonymous reviewer of Moniz's monograph for Archives of Neurology and Psychiatry (it is thought to be Walter Freeman) was also very impressed with Moniz's results (Anonymous 1936, 1413), as was Gaston Ferdière, one of the first to perform a leucotomy in France. He went ahead persuaded by the results Moniz had obtained, although he also had doubts about the theoretical basis of the procedure (Ferdière 1940, 82). And finally the development in Puusepp's thinking, the man who ventured into psychosurgery some twenty years earlier, is particularly interesting in this context. At first, he was so discouraged by his own experience that he launched an attack on Burckhardt without admitting that he himself had also operated on patients. However, on learning about Moniz's results, he owned up to his early attempt and took up psychosurgery again (Puusepp 1937). In a short time a number of other surgeons repeated the operation and Moniz's results were broadly confirmed ${ }^{17}$.

\section{Theoretical considerations}

Thus it would seem that the initial acceptance of, or at least readiness to repeat the operation, owed much to the results that Moniz reported. However, there were other differences between the work of Burckhardt and Moniz that it will be interesting to explore. They did not necessarily play a role in making one more acceptable than the other but, nevertheless, they were of considerable consequence. One concerns the respective theoretical positions.

Burckhardt attempted to square his rationale for psychosurgery with the developments of his time, with the type of approach that was advocated by Meynert, Wernicke and others of that period, namely, that mental illness has an underlying anatomical pathology and that various symptoms have a precise cerebral locality. He reasoned that specific symptoms could be eliminated by removing appropriate cortical centres. The first patient he presented was a 51-year-old woman who for sixteen years had been suffering from 'chronic raving madness'. She was abusive, insulted everyone in sight, she yelled, kicked, spat. Burckhardt proceeded to operate on her four times in a period of little over a year. All the operations were carried out on the left side of the brain and in the first three operations 5,2.5 and 5.5 grams of

17 When psychosurgery was performed on a large scale, fatalities did occur, as much as $4 \%$ (Tooth/Newton 1961). 
cortex were removed. Some symptoms persisted, particularly verbal assaults, and Burckhardt decided that one more operation was needed. 'I concluded that there was a pathological state of agitation in the word centres for word formation - I thought I could conclude this because of the persistence of verbigeration, or, more correctly, logorrhoea. I further concluded that, in pursuit of my original plan, the next location to attack had to be the region of the motor speech centres' (Whitaker et al. 1996, 284). In the fourth, last operation, 1.5 grams of cortex of the pars triangularis of Broca's area were removed.

Moniz belonged in a different era and his reasoning was different. He did not think that the path traced by the earlier brain anatomists would lead to a satisfactory outcome. So, while he praised Kleist for his commitment to the 'illness of the brain' view of mental illness, he did not agree with Kleist's 'excessive' topography. Moniz did not take recourse to more holistic concepts such as those of Hughlings Jackson or Kurt Goldstein, either. Instead he developed a novel way of approaching the question. He based his thinking on the neuron theory of Ramón y Cajal and the phenomenon of conditioned reflex that Pavlov had demonstrated. He argued that 'nerve fibrils and synapses are [...] fundamental organs of thought' (Moniz 1949a, 88) and that since there is 'a certain correlation between psychical alterations and chemical alterations that take place at the level of synapses [we can conclude that] mental illnesses also have their principle at the level of synapses' (Moniz 1949a, 90). More specifically he argued that obsessive thoughts are due to a fixation of synaptic connections, to abnormally repetitive and overactive circuits that are formed much in the way the conditioned reflex is created. Cutting those fixed connections should free the patient from the obsessive behaviour. Reports on psychological symptoms that follow injuries to the frontal lobes convinced Moniz that it is the frontal lobe that 'stands in close relation to psychic life' and therefore this is where the surgeon's attention should be directed ${ }^{18}$.

18 This account of Moniz's theory is culled from a number of his writings. First there was the monograph and a number of shorter accounts in various journals, which all came out in 1936 (Moniz 1936a and 1936b). In those earlier publications Moniz concentrated on neurological findings about the frontal lobes. The idea about fixed neuronal circuits and faulty chemical signalling at the synaptic level is already mentioned in the first monograph and the briefer communications that appeared that year in medical journals. But Rámon y Cajal and Pavlov are not mentioned. In later writings (Moniz 1945, 1949a, 1949b, 1950, 1954) Moniz seemed keen to underline links with neuroscientific discoveries and Pavlov and Cajal become prominent. At this stage Moniz concentrated more on how the supposed fixed neuronal circuits are formed and less on the frontal lobes (in fact, he predicted, correctly, that psychosurgeons would also target other sites [Moniz 1945, xv]). The structure of the argument, namely, that mental illness is due to fixed neuronal circuits and faulty synaptic signalling, remained the same throughout. 
Moniz's theory consists of no more than the old associationism mapped onto neural circuits. This was not particularly innovative; mapping a psychological theory onto neurological findings has been, in a way, standard procedure $^{19}$; what made the difference and had great consequences was what Moniz went on to state:

[The] mental troubles must have [...] a relation with the formation of cellulo-connective groupings, which become more or less fixed. The cellular bodies may remain altogether normal, their cylinders will not have any anatomical alterations; but their multiple liaisons, very variable in normal people, may have arrangements more or less fixed, which will have a relation with persistent ideas and deliria in certain morbid psychic states. (Moniz 1936a, 45)

This needs underlining. According to this way of reasoning the neurons are normal and have no anatomical alterations; they are not damaged. The problem is that some of the neurons at times misbehave; mental illness is a brain in 'neuronal disarray' (Moniz 1948, 466). In brains of normal people neurons behave properly, that is, they form a great variability in connections; but, for example, obsessive thoughts, which so often torment the mentally ill, are due to neuronal circuits getting fixated; but to repeat, they are in no way anatomically altered. This new way of conceiving the problem did not go unnoticed. Walter Freeman, the likely reviewer of Moniz's monograph for Archives of Neurology and Psychiatry, seized upon this aspect of the theory: 'the cell bodies may remain normal and their processes show no anatomical alterations, but their multiple connections [...] may develop more or less fixed arrangements ...' (Anonymous 1936, 1413).

To sum up briefly: Burckhardt believed that the structure of the brain and the structure of the psyche must coincide and he based his operation on the conception that psychiatric illness is an outcome of a detectable (eventually) local anatomical pathology. Moniz based his operation on a theory according to which mental disturbances are due to faulty synaptic circuits, which were not detectable by any known diagnostic procedures.

The theoretical shift from Burckhardt to Moniz led to a significant change. Since the fixed neuronal circuits that are responsible for mental aberrations are not themselves damaged, the old neurological procedures that sought demonstrable anatomical changes were no longer of any use. In Burckhardt's time it would be expected, however tacitly, that studies of the brain would eventually confirm the correctness of the procedure, in Moniz's scheme no such confirmation was expected because the fixated synaptic roots are not

19 In a similar vein, Wilhelm Griesinger, the first great proponent of the 'illness of the brain' conception of insanity, mixed the reflex arc with Herbartian psychology of image formation (Griesinger 1867). The use of the reflex arc was also very common in nineteenth-century Britain (Jacyna 1982). 
anatomically altered. To put it differently, Burckhardt's attempt was placed within an epistemological limit that rendered the theory falsifiable. And this is what in effect happened. Once it became more or less clear that the efforts of the late nineteenth-century pathologists would not yield the expected demonstration of a coincidence between the anatomy of the brain and mental functioning, psychosurgery in the mould of Burckhardt lost its rationale ${ }^{20}$. Moniz removed the requirement that the correctness of the procedure should be verifiable by known neurological and anatomical procedures. In effect, he was launching an open-ended experimental surgery programme. One should note that Moniz did not so much as suggest a way of thinking about how some process of verification could be instituted. This is the more striking if we bear in mind that his earlier work on angiography contributed so much to the diagnostic and verification problems in neurology and neurosurgery.

\section{Discontinuity between neurology and psychosurgery}

Moniz's nineteenth-century predecessors assumed that there was continuity between the neurological symptoms and psychiatric symptoms, and that this continuity would be confirmed by studies of the brain. This was reflected in their careers. For example, Meynert succeeded in detecting lesions in the brain responsible for the syphilis-induced general paresis and thought he could uncover the same correspondence between brain pathology and mental illness; similarly, early in his career Wernicke was successful in localising a speech area in addition to the one earlier localised by Paul Broca and thereafter he sought to localise mental faculties following the same methodology. And finally, in the case of Burckhardt himself, there is a logical continuity between psychosurgery and his earlier studies on sensory aphasia and on functional centres of the brain and their relation to psychiatry and neurology.

However, there is no such continuity in Moniz's career, nothing in his earlier neurological work anticipated psychosurgery. The theory about the faulty synaptic connections that was the basis for the psychosurgical operation had nothing to do with any of his earlier research. In fact, Moniz himself stated that angiography and leucotomy are 'quite apart' (Moniz 1949a, 307). And indeed, when we see the preparatory work that went into angiography and psychosurgery we are struck by how different they are.

20 In the 1940s, topectomy, a technique similar to Burckhardt's, was introduced. This does not mean that the surgeons were following Burckhardt's reasoning. It is rather that at this stage they were in full experimental swing and targeting various sites. 
Angiography was solved after a long period of experimentation. Tests on animals began in 1924, followed by experiments on brains of cadavers and then patients in the clinic; one patient died in the earlier phase of experimentation. The first image of intracranial circulation in a living patient was obtained in 1927; three years after the first trials had begun. The path to psychosurgery could not have been more different; Moniz decided to go ahead with it 'after a period of solitary meditation', two years of it (Moniz 1949b, 15). There was no other preparatory work and there could not have been, bearing in mind the speculative character of the operation. So, although neurosurgery and psychosurgery are both operations on the brain, their respective methodological procedures and the conceptual frameworks are so different as to make one question the apparent affiliation between the two. The conclusion that seems obvious is that prefrontal leucotomy was not a neurological operation for mental illness as is still sometimes stated ${ }^{21}$; neurologists were not (and are not) in the habit of surgically entering the brain without first satisfying themselves that the target of the intervention could be well and verifiably identified (even if only after the postmortem) ${ }^{22}$. Within the parameters of proper neurological practice leucotomy was not a legitimate procedure.

But if it was not neurology as it was (and is) understood, then what was the nature of Moniz's speculation? At the time he was putting together his theory there was no name for this type of reasoning. Subsequently a theory that seeks to relate human behaviour to neural circuits and chemical reactions of the synapses has become known as a neuropsychological theory. However, neuropsychology deals mostly with questions of cognition and has little to say about mental illness ${ }^{23}$. It would therefore seem more correct to call Moniz's speculation a neuropsychiatry because here it is the question of viewing pathological symptoms as signs of neuronal malfunctioning. However, already in the nineteenth century psychiatrists who also dealt with neurological diseases were called neuropsychiatrists. Moniz differed from them in that he targeted the brain directly, and so he should be called an experimental neuropsychiatrist. The difference between neuropsychology and experimental neuropsychiatry is considerable. Neuropsychology never

21 '[P]sychosurgery is really a misnomer; leucotomy is neurologic surgery applied to mental patients' (Damasio 2000,108).

22 There is a grey zone, however, which involves experimental surgery for Parkinson's, epilepsy and intractable pain.

23 D. O. Hebb who was the first to use the term 'neuropsychology' in a title (Bruce 1985). The work in question (The Organisation of Behaviour. A Neuropsychological Theory) has a chapter on mental illness. But can an account based on two chimpanzees 'apparently suffering from neurosis or psychosis [?!]' (Hebb 1949, 245) be of much use to a psychiatrist? 
rejected the findings of early psychology schools, in fact, it benefited (and still benefits) from the investigations of introspective and experimental psychologists. These made advances in breaking down the stream of psychological phenomena into analysable units and developed a considerable experimental know-how; all these advances were put to use in neuropsychological investigations ${ }^{24}$. Experimental neuropsychiatry rejected the knowledge painstakingly gathered by clinical psychiatrists. It also broke with the past anatomico-pathological studies and had no other methodology to take its clues from; it was indeed a child of 'solitary meditation'.

\section{Clinical experience}

Moniz arrived at the idea of psychosurgery after two years of solitary meditation. What exactly this meditation involved is not entirely clear, but nothing suggests that it was the patients that Moniz was thinking about, as he did not work in an asylum and his knowledge of the psychiatric clinic was minimal. In fact, there is little evidence that mental illness really interested Moniz; at least this is what his long list of publications suggests. Moniz wrote well and with ease, he clearly liked writing. Apart from his extensive scientific output (four monographs and well over 200 papers) there is a book on card games, an account of his childhood, essays on art, a scientific autobiography; psychoanalysis and hypnosis also attracted his attention. However, until the monograph on psychosurgery there is practically no word on psychiatry proper, we will not find in his writings a single clinical study, nor any other sign of genuine interest in the matter.

That Moniz did not seem particularly intrigued by mental illness can also be gleaned from a revealing comment in his scientific autobiography. He recounts his visit to Turin. He was there as the guest of Emilio Rizzatti who was one of the most enthusiastic adherents to the new treatment. 'A curious thing,' noted Moniz about one of the servants employed by Rizzatti. 'She was a leucotomised patient' (Moniz 1949a, 200). And that is all he has to say. Moniz does not display any sign of curiosity whatsoever; he does not try to find out more about the patient; what she was like before the operation, he

24 For example, the distinctions between procedural and declarative memory, or eidetic and linear memory were first made through introspective studies. It is important to remember that the phenomena that neuroscientists study are first named, described and deemed worthy of investigation on the basis of nonneuroscientific criteria. The various experiments that are set up to then study aspects of these different types of memory, for example, rely on the bag of tricks of the nineteenth-century experimental psychologists like Ebinghaus and Wundt. 
makes no attempt to speak to her. (Or, at least, he does not tell the reader anything of the sort.)

Much in keeping with this, we find that the psychosurgery operations were quite a rapid affair. The patients were sent to Moniz's neurological clinic from the nearby psychiatric hospital and they were normally operated on the day of their arrival. Typically within ten days they were sent back ${ }^{25}$. The postoperational observation was clearly very superficial, and Moniz was not involved in any follow-up. A clinical psychiatrist would find all this rather odd; to the likes of Kraepelin, Bleuler, Jaspers or the man much admired by Moniz, Kleist, for that matter, clinical experience was the bedrock of their metier $^{26}$.

It is interesting to see how Ivan Pavlov approached a similar situation for, towards the end of his long and illustrious career, he, too, became interested in problems of mental illness. His first step was to arrange clinical sessions in a psychiatric clinic where he could study cases. He discussed them with psychiatrists. Minutes of his biweekly Wednesday Clinical Colloquia show him seeking various clarifications, wanting to know which symptoms were characteristic of various diagnoses, and so on (Windholz 1993, 514). He studiously read the classics of his time, Kraepelin, Bleuler, Kretchmer. In brief, Pavlov placed himself very much in the role of a pupil. Thereafter he reviewed various treatments that had been devised by psychiatrists to see which one in his view was the most suitable. (He believed mental illness to be an effect of the irritation of the cortex and so thought the best approach was the prolonged sleep treatment developed in the 1920s by the Burghölzli psychiatrist Jakob Klaesi [Windholz 1993,522].) Pavlov had clear views about the organic causes of mental illness, but he certainly was not trigger happy ${ }^{27}$, and the idea that one can say something pertinent about mental illness, let alone treat it, without any firsthand clinical experience never occurred to him; but this was how Moniz proceeded.

25 The duration of stay of the 20 operated patients in Moniz's clinic was as follows: 8 days, 26 days, 22 days, 8 days, 6 days, 14 days, 6 days, 7 days, 8 days, 11 days, 7 days, 5 days, a month and a half, one month, a month and a half, 9 days, 9 days, 11 days, 9 days, 11 days. (These figures may not be absolutely exact as the date of admission and discharge is not always clearly indicated.) (Moniz 1936)

26 Moniz admired Kleist for firmly adhering to the 'illness of the brain' conception of mental illness, but there is no indication that he took the trouble to find out what cycloid psychoses, a clinical term coined by Kleist, were.

27 There is a rather amusing story about one of the patients that Pavlov and other psychiatrists observed. The man had undergone a religious conversion some ten years earlier and his subsequent comportment landed him with a diagnosis of paranoia. Pavlov thought there was nothing wrong with him, as far as he could see the man just talked like a typical Orthodox believer. The patient was brought in for another observation. Pavlov did not change his mind, 'a completely normal human being' was his view, the psychiatrist (Ostankov) changed the diagnosis from paranoia to paranoid psychopath (Windholz 1996, 160). 
It would seem that Moniz's attitude to clinical experience has its origin in a particular streak that animates some of the neuroscientific thinking,namely, the conviction that it is possible to create a science of the mind that takes no recourse to introspection, a science that will eventually eliminate all evidence judged as subjective. This is what inspired Gall's phrenology and it has remained part of a neuroscientific makeup ${ }^{28}$. From this point of view it is quite consistent to argue that one can treat the mentally ill without any knowledge of, or interest in their subjective state of mind.

\section{From neurosurgery to psychosurgery}

Pavlov evidently had respect for psychiatrists and recognised their expertise, but not Moniz. This was the nub of a conflict that developed between him and a Lisbon psychiatrist José de Matos Sobral Cid. Cid held the Chair of Psychiatry and was director of the Bombarda asylum. He at first agreed Moniz could operate on his patients, but later he refused to cooperate ${ }^{29}$. For the second trial Moniz had to find patients in another hospital. It was this second group of twenty-one patients that Furtado presented at a session of the Société Médico-Psychologique in Paris. Cid also travelled to Paris to attend the session and he unleashed a harsh critique of the new technique. He doubted whether the changes in the patients were anything else than a reaction to shock, much the way soldiers react to head injuries. He also found that after the operation the patients were 'diminished', that there was a

28 I am not sure I would have thought of this so bluntly had I not come across this way of putting the matter by the French neuroscientist Jean-Pierre Changeux: 'His [Gall's] aim was to analyse the functions of the brain and to localise them without recourse to introspection' (Changeux 1983, 25). It should be noted, however, that it was not neuroscience that was responsible for the demise of introspection; this was due to internal difficulties of the various introspective methods and the advent of behaviourism, which brought about a change in interests and aspirations of psychologists (Danzinger 1980).

29 José de Matos Sobral Cid (1877-1941). He studied medicine in Coimbra where he knew Egas Moniz. He completed his studies in 1900 and began work at the Faculty of Medicine in Sanitary Medicine, Paediatrics and Maternity. In 1911 he was transferred to the Lisbon Faculty of Medicine and became deputy director of the Bombarda asylum. In 1919 he became director of the Faculty of Medicine. In 1922 he became director of the Bombarda asylum and the following year was named Professor of Psychiatry. He remained in these posts until his sudden death in 1941.

Cid wrote on forensic psychiatry, on organisational and educational problems of psychiatry, and a number of studies in clinical psychiatry, the most interesting dating from 1923/24 (Sobral Cid 1923,1924a, 1924b). He was influenced by the works of Bleuler, Jaspers, Kretchmer and was much interested in depth psychology. In his 1901 doctorate he wrote:'One should look for the morphology of madness away from the nervous system' (Fernandes 1981, 2). In view of this it is difficult to understand how Moniz managed to convince him that psychosurgery could work. 
'degradation of personality'. The patients of the first group that Moniz operated on came from Cid's hospital, and that is where they returned after the operation, so Cid knew what he was talking about. As to the theory of 'functional fixations', he thought it to be no more than 'pure cerebral mythology' (Moniz/Furtado 1937, 306).

Cid particularly resented Moniz's haughty dismissal of the psychiatric profession and the invasion of the neurologist into his domain. Moniz was well aware of this. He wrote to Walter Freeman, 'one day, however, abandoning neurology for a moment, I resolutely penetrated the ambience of psychiatry, that is, the special studies of the Faculty that had been entrusted to Sobral Cid. [...] The professor of the chair of Psychiatry could not have been pleased' (Moniz 1978, 441). He thought that Cid's objections were a jealous reaction to the successes that he had obtained with the revolutionary surgery and, at any rate, Cid's objections could not carry weight, as in his view psychiatrists were hopelessly inept at treating mental illness. Cid himself was 'afflicted by an excessive psychiatric phraseology and has been taken, in specialist terms, at times interesting, with literary tendencies, in an ambience of linguistic erudition, but far from medical reality, forgetting completely that psychiatry is a branch of a science that we exercise' (Moniz 1978, 437), wrote Moniz to Freeman. A new approach that would recognise that psychiatry is merely a branch of neurosciences was needed. This new approach was psychosurgery, the avantgarde of experimental neuropsychiatry, and in this new scheme of things traditional psychiatrists, who were not trained surgeons, were reduced to the role of junior partners or hostile spectators. That is how the Professor of Psychiatry at the University of Lisbon felt.

With an attitude like this Moniz had a problem, since to launch his psychosurgery programme he had to convince the sceptical psychiatrists to let him operate on their patients. He had to resort to a great deal of arm-twisting. Moniz, it should be added, could not count on any favours from Salazar's regime, as he was known to be hostile to the new fascist order. However, he had behind him a successful career in the diplomatic service and had been active in politics, so he knew how to go about persuading others. And, by all accounts, Moniz cut a formidable figure. Walter Freeman, who was not easily intimidated, was apparently in awe of him; he went as far as to say that he would not have ventured into psychosurgery had he not met Moniz in person (Pressman 1998, 76), and whenever he travelled to Europe he always made a point of going to Portugal to visit Moniz. Finally, he had the authority of a neurologist and scientific investigator of the first rank. Ferdière, the early French leucotomist, explained that he knew of and agreed with Sobral Cid's contention that Moniz's theory was 'brain mythology', but in view of 
the results that Moniz reported and of 'the scientific probity of Professor Egas Moniz, inventor of cerebral arteriography', he overcame his misgivings (Ferdière 1940, 82).

Still, how is it that such a strange approach (from the point of view of a clinical psychiatrist) was so widely accepted? After all, Moniz's powers of persuasion could only go so far. Here we come to one final factor that was critical to the quick success of psychosurgery. It was noted earlier that the psychiatric Zeitgeist would seem to have been less favourable to Moniz than to Burckhardt. And certainly that is how it at first looked. Moniz was greeted with hostility; Ferdière, who like Moniz presented his case at the Societé Médico-Psychologique, was also given short shrift, 'the subject of this communication leaves me with some dread' was one response. Ferdière was severely criticised for the fact that the patient operated on had been diagnosed ill for a few months only and hospitalised for just one and a half months. It was also suggested to him that his understanding of catatonia was poor (the patient operated on was catatonic) (Ferdière 1940,87f. ${ }^{30}$. However, the point is that it was not the psychiatric milieu that decided the issue. In the late 1880s surgical intervention in the brain was in its infancy; by the time of Moniz neurosurgery had made immense progress. The likes of Harvey Cushing, Walter Dandy, Hugh Cairns and Wilder Penfield were pushing the boundaries of the possible at an impressive rate. Consequently, there was a great number of surgeons who would have found leucotomy easy to perform, many were very intrigued by the new challenge and tried their hand at it (including Dandy, Penfield and Cairns). Most of the pioneers of the new procedure had a similar scientific profile to Moniz; they were accomplished neurologists or neurosurgeons but had limited, if any, experience of the psychiatric clinic. For example, Walter Freeman, James Watts and John Fulton, who were the main driving force on the American scene, were a neuropathologist, neurosurgeon and neurologist respectively.

And it was the neuroscientists who made sure that psychosurgery was given the ultimate scientific seal of approval, the Nobel Prize. The committee deliberated the matter in 1949. By then a number of studies confirmed that the objections first raised by Sobral Cid had substance; the outcome continued to be impossible to predict and reports on the postoperational state of patients frequently spoke of a loss of some key affective faculties; all too

30 Ferdière seems to have abandoned psychosurgery but retained a 'taste' for shock treatments. Between 1943 and 1946 he had in his charge in the Rodez asylum in the south of France a certain Antonin Artaud. Ferdière was friends with some artists and writers, Desnos one of them, and he had met Artaud in the thirties. When he had the illustrious patient in his care, he took special interest in him. It still did not stop him from administering some 60 electroshock treatments. The treatment made Artaud howl in rage. 
often the patients seemed apathetic and lacking in initiative.Perhaps the most telling was the 12-year follow-up study on the second group of patients that Moniz operated on; it revealed quite clearly that the long-term results were far less satisfactory than the ones presented at the Paris meeting in 1936 (relapses, epileptic seizures, high rate of early deaths [Furtado 1949] ${ }^{31}$. However, it was the recommendation of the eminent Swedish neurosurgeons Herbert Olivecrona ${ }^{32}$ and Gösta Rylander that was decisive and the prize was awarded to Moniz ${ }^{33}$. This seal of approval did not secure universal acceptance as the following year psychosurgery was banned in the Soviet Union and condemned by the Vatican.

\section{Moniz in the history of psychiatry}

Insulin coma, convulsive shock, malaria fever, electroshock and finally psychosurgery, this is the line of shock treatments as they appear in most histories of psychiatry. Psychosurgery is practically always presented as the last in the line, even though electroshock was introduced by Ugo Cerletti two years after Moniz's leucotomy. It is presented as the last, because it is the most extreme. And so it is, only that the other treatments and psychosurgery do not quite fall into a neat line. Psychosurgery is more than just another shock treatment; it differs from the previous treatments in relation to the psychiatric clinic $^{34}$. Whatever the assessment one makes of the earlier treat-

31 Diogo Furtado, who presented the follow-up, became a staunch adversary of the procedure (Fernandes 1983, 77). Moniz commented on Furtado's findings by saying that it was only at the time of the presentation at the Congress that he had become aware of them (Moniz 1949a, 606), which indicates that he was not even curious enough to enquire how the patients he had operated on were faring.

32 Olivecrona gave the presentation speech at the prize-giving ceremony.

33 These last three paragraphs need to be nuanced. As they stand they suggest a complete schism between the psychiatrists and the neurosurgeons. While the hostility of Sobral Cid towards Moniz was real, and many others felt the same, it would not be true to say that no psychiatrist could want to have anything to do with psychosurgery, after all Burckhardt was an alienist, and, for example, the Italian Armano Fiamberti, the inventor of the transorbital technique (Fiambierti 1937, 1939), was an experienced psychiatrist. Still, it is remarkable how the psychiatrists' early incredulity and hostility turned into almost universal acceptance. Jack Pressman gives a good account of how Walter Freeman went about wining over the psychiatric community in the United States (Pressman 1998). One explanation is that it helped psychiatrists deal with unmanageable overcrowded wards. But there is more to it. In France, for example, psychosurgeons could count on the support of Eugène Minkowski. Henri Baruk who fought tooth and nail to have psychosurgery banned must have felt utterly bemused to see the grand phenomenologist in his opponents' camp. 'In the fight that I led I had almost the totality of the psychiatric community against me', said Baruk in his autobiography (Baruk 1990, 247). It would take a separate study to fully understand how this change of view of the psychiatrists could have come about.

34 This was already noted at the same session at which Sobral Cid expressed his misgivings about leucotomy. 
ments, they at least had the merit of being devised after an accumulation of some clinical data. Sakel developed insulin therapy after it was noticed that accidental insulin comas tend to quieten down agitated patients; Meduna induced convulsions on the basis (mistaken) that epilepsy and schizophrenia are antagonistic; Wagner-Jauregg's treatment of inducing a malaria fever was based on long-known observations of some spontaneous recoveries of psychotics after attacks of malaria. Psychosurgery had nothing to do with the psychiatric clinic. It was based on a few contradictory observations from a neurological clinic where changes in behaviour and personality that occur after injuries to the frontal lobes were noted, and on a neuroscientific speculation that was in no way related to these observations.

If one were to seek a lineage of psychiatric 'treatments' in which lobotomy should be placed, then it would have to be together with various other surgical interventions that entered the clinic, thyroidectomy, sterilisation, castration, clitoridectomy; the logic is after all the same, mental illness is due to a malfunctioning of some organ and a surgical intervention on the offending organ is performed ${ }^{35}$. All these treatments were at one time or another favourably received by (at least parts of) the scientific community ${ }^{36}$. And, finally, all previous shock therapies were not only born within the psychiatric milieu, it was also where these treatments were debated and assessed. And this was also the context in which Burckhardt worked. Unlike Moniz, he was an alienist; it was to other alienists that he presented his work and it was the milieu of the alienists that forced him to abandon it.

Yet Moniz is a pivotal figure. His foray into the field of psychiatry left a deep mark and led to a number of new developments. First, Moniz opened the way for direct intervention in the brain. It had been attempted before, and others had thought of it; but the supremely confident Moniz went ahead with a series of operations and in very short time what was thought of extreme, barely probable and highly uncertain became common practice.

35 This is neither a fanciful nor provocative view. Freeman and Watts in their introductory comments to Psychosurgery plainly place the procedure in the lineage of other surgeries that were performed within the psychiatric clinic:

The surgery of mental disorder has returned to the brain after following a devious route through the other parts of the body, stopping at this, that, or the other organ until each of these was shown to be without causative relationship to mental disorders.

(Freeman/Watts 1942, 5)

In this brief, few pages introduction, insulin or malaria treatments do not get a mention (though 'the passive mysticism of psychoanalysis' does [Freeman/Watts 1942,3]).

Joel Braslow's study (Braslow 1997) also puts psychosurgery within the context of other surgical interventions.

36 Although Bechterev and Puusepp condemn Burckhardt's brain surgery, they accept as an established fact the link between sexual and other organs and mental illness and think that surgical interventions on these organs are legitimate (Bechterev/Puusepp 1912). 
And, although psychosurgery was largely discredited, the idea of direct brain intervention has not gone away and the procedure (albeit in a modernised version) is again on the increase.

The theoretical changes were considerable too. From the beginning Moniz's reasoning was thought to be vague or denounced outright as 'brain mythology'. Still, in suggesting that mental illness can be the result of chemical reactions at the synaptic level and aberrant neuronal circuits ('radical neuronism' [Fernandes 1983,132]), Moniz hit upon an idea that has remained ever since one of the key components in the thinking of neuropsychology. And when we read in a much later account that psychosurgery is a technique that is assumed to break up the reverberating circuits of the limbic system and thereby stop the self-perpetrating cycle of emotional stimulation that may be causing repetitive obsessions and compulsions' (Andreasen 1984, 214), it is hard not to see that Moniz's logic has been retained. However, it was not only the question of a novel idea that proved to be lasting; Moniz's neuronal theory of mental illness effectively brought to an end the anatomico-pathological model. The long and fruitless search for anatomical lesions was more or less abandoned and the hunt for the aberrant neural circuits began.

Moniz argued for the superiority of psychosurgery over other shock treatments, such as cardiozol and electroshock. These, he pointed out, hit the brain en masse, and therefore they were of little scientific value; psychosurgery, by contrast, targets specific areas of the brain and the results of these procedures should further the understanding of how the brain functions (Moniz 1949a, 327). This is unmistakably a neuroscientific argument and a rationale for a neuroscientific programme. And indeed, psychosurgery gave neuroscientific research a tremendous push. On the one hand it was introduced as a treatment for mental illness, on the other hand it was a central plank of an extensive research programme ${ }^{37}$. It must be said that psychiatrists did not profit from this research as much as neuroscientists did, and the patient population even less $\mathrm{so}^{38}$.

The mark that Moniz left goes deeper though. He came from a generation that established a clear professional demarcation; the neurologist had little

37 Pressman gives an account of how Fulton developed (with aid from the Rockefeller Foundation) a neuroscientific research programme in which psychosurgery was to play a central role (Pressman 1998).

38 At the first International Conference of Psychiatry held in Paris in 1950 the communications on psychosurgery concentrated principally on the lessons on the anatomy and physiology of the brain rather than its clinical value (with the exception of the presentation of Walter Freeman). The title of the session is indicative enough: 'Cerebral anatomo-physiology in the light of lobotomies and topectomies'. One communication was simply entitled 'Anatomical lessons from prefrontal leucotomy. A report on the investigation of 122 brains' (Meyer 1950). 
reason to be concerned with the psychiatric clinic, the psychiatrist was well aware of the neurologist's sphere of expertise. The two professions were developing independent architectonics and the apparent overlaps between them were becoming less obvious. The introduction of psychosurgery changed that; it brought about a rearrangement in epistemological rules and a new structure of authority within the psychiatric profession. These changes still need to be studied and their consequences assessed.

\section{Bibliography}

Amaral, M. Almeida, O tratamento cirúrgico das doenças mentais (Lisbon 1945)

Andreasen, Nancy C., The Broken Brain. The Biological Revolution in Psychiatry (New York 1984)

Anonymous, Archives of Neurology and Psychiatry 36 (1936) 1413

Baruk, Henri, Mémoires d'un neuropsychiatre (Paris 1990)

Bechterev, Vladimir/Ludvig Puusepp, ¿La chirurgie des aliénés`, Archives Internationales de Neurologie (1912) 1-17, 69-89

Beckmann, H./E. Franzek, «La nosologie de Wernicke-Kleist-Leonhard et son importance dans la recherche et la pratique clinique, dans: Pichot, Pierre/Werner Rein (éds), L'approche clinique en psychiatrie (Le Plessis-Robinson 1999) 585-618

Berrios, German E., 'Psychosurgery in Britain and elsewhere: a conceptual history', in: Berrios, German E./Hugh Freeman (eds), 150 Years of British Psychiatry 1841-1991 (London 1991) 180-196

- 'The origins of psychosurgery: Shaw,Burckhardt,Moniz', History of Psychiatry 8 (1997) 61-81

Bleuler, Eugen, La Schizophrénie, rapport au congrès de médecins aliénistes et neurologistes de France et des pays de langue française, $X X X^{e}$ session (Paris 1926)

Braslow, Joel, Mental Ills and Bodily Cures: Psychiatric Treatment in the First Half of the Twentieth Century (Berkeley 1997)

Brickner, Richard M., 'An interpretation of frontal lobe function based upon the study of a case of partial bilateral frontal lobotomy', Research Publications - Association for Research for Nervous end Mental Disease 13 (1932) 259-351

- The Intellectual Functions of the Frontal Lobe: A Study Based Upon Observations of a Man After Partial Frontal Lobectomy (New York 1936)

Bruce, Darryl, "On the origins of the term "neuropsychology", Neuropsychologia 23 (1985) 813f.

Changeux, Jean-Pierre, L'homme neuronal (Paris 1983)

Choroschko, W.-K., 〈Doctrine des lobes frontaux d'après trente années de recherches personnelles>, Annales Médico-Psychologiques xv, II (1935) 383-401

Damasio, Antonio, 'Egas Moniz, pioneer of angiography and leucotomy', in: Pereira, Ana L./ João R. Pita, J.R. (eds), Egas Moniz em Livre Exame (Coimbra 2000) 97-109

Danzinger, Karl, 'The history of introspection reconsidered', Journal of the History of the Behavioural Sciences 16 (1980) 241-262

Ellenberger, Henri, The Discovery of the Unconscious. The History and Evolution of Dynamic Psychiatry (New York 1970)

Ferdière, Gaston, «Résultats immédiats de la leucotomie préfrontale dans un cas de schizophrénie avec stupeur catatonique>, Annales Médico-Psychologiques XV, I (1940) 81-89

Fernandes, Barahona, «Sobral Cid, mestre da psicopatologia`, O Médico 100 (1981) 5-28 (quoted from a separata pp. 1-36)

- Egas Moniz, pioneiro de descobrimentos medicos (Lisbon 1983)

Fiamberti, Amaro M., 〈Proposta di una tecnica operatoria modificata e semplificata per gli interventi alla Moniz sui lobi prefrontali in malati di mente>, Rassegna Studi Psychiatria 26 (1937) 797-805 
- 〈Considerazioni sulla leucotomia prefrontale con il metodo transorbitario〉, Gior di psychiat e di neuropat 67 (1939) 291

Freeman, Walter/James W. Watts, Psychosurgery (Springfield 1942)

Fulton, John F., Frontal Lobotomy and Affective Behaviour (New York 1951)

Furtado, Diogo, 'Results of leucotomy. A twelve-year follow-up', Psychosurgery. First International congress (Lisbon 1949) 171f.

Gozzano, M., «Bibliografie`, Rivista de Neurologia, Febbr. (1937) 90-92

Griesinger, Wilhelm, Mental Pathology and Therapeutics (1867) (facsimile reprint, New York 1965)

Hebb, Donald O., The Organisation of Behaviour. A Neuropsychological Theory (London 1949)

Jacyna, Steven, 'Somatic theories of mind and the interests of medicine in Britain, 1850-1879', Medical History 26 (1982) 233-258

Jaspers, Karl, General Psychopathology (Manchester 1963)

Joanette, Yves/Brigitte Stemmer/G. Assal et al., 'From theory to practice: the unconventional contribution of Gottlieb Burckhardt to psychosurgery', Brain and Language 45 (1993) $572-587$

Meyer, A., 'Anatomical lessons from prefrontal leucotomy. A report on the investigation of 122 brains', Congrès International de Psychiatrie (Paris 1950) 107-141

Moniz, Egas, Diagnostic de tumeurs cérébrales et épreuve de l'encéphalographie artérielle (Paris 1931)

- L'angiographie cérébrale. Ses applications et résultats en anatomie, physiologie et clinique (Paris 1934)

- Tentatives opératoires dans le traitement de certaines psychoses (Paris 1936a)

- 〈Essai d'un traitement chirurgical de certaines psychoses〉, Bulletin de l'Academie de Médecine 115, 9 (1936b) 385-342

- 〈Prefácio〉, in: M. Almeida Amaral, O tratamento cirúrgico das doenças mentais (Lisbon 1945) $\mathrm{i}-\mathrm{Xv}$

- 〈O domínio de delírio e da alucinação〉, A Medicina Contemporânea 12 (1948) 465-483

- Confidências de um Investigador Cientifico (Lisboa 1949a)

- 'How I came to perform lobotomy', Psychosurgery. 1st International Conference (August 4th-7th 1948) (Lisbon 1949b) 15-21

- Conferências médicais e literarias, vol. III 〈Ramón y Cajal〉 (Lisbon 1950)

- A Leucotomia esta em causa (Lisbon 1954)

- ¿O vagoroso desenvolvimento da leucotomia pré-frontal em Portugal , intr. Walter Freeman, in: Centenário de Egas Moniz, vol. II (Lisboa 1978) 423-445

Moniz, Egas/Diogo Furtado, «Essais de traitement de la schizophrénie par la leucotomie préfrontale>, Annales Médico-Psychologiques II (1937) 298-309

Neumärker, Klaus-Jürgen/Andreas Joachim Bartsch, 'Karl Kleist (1879-1960) - a pioneer of neuropsychiatry', History of Psychiatry 14 (2003) 411-458

Perris, C., 'Leonhard and the cycloid psychoses', in: Berrios, German E./Roy Porter (eds), A History of Clinical Psychiatry (London 1995) 421-430

Pressman, Jack D., Last Resort: Psychosurgery and the Limits of Medicine (Cambridge 1998)

Puusepp, Ludvig, ¿L'Alcune considerazioni sugli interventi chirurgici nelle malattie mentali`, Giornale Accademia Medicina Torino 100 (1937) 3-16

Riechert, T., 'Technique and Influence of Stereotactic Surgery in Psychosurgery', in: Centenário de Egas Moniz, vol. I (Lisboa 1977) 213-221

Rizzatti, Emilio, «L'operazione frontale bilaterale di Egas Moniz nelle psicosi postencefaliche〉, Schizophrenie 6 (1937) 203

- /G. Croce/G. Moreno/G. Borgarello/M. Pennacchietti/V. Martinengo, <Risultati tecnici di 400 interventi sul sistema nervoso centrale>, Rivista Italiana di Endocrino e Neurochirurgia vol. IV (1938) XVI 470-475

Sacks, Oliver, An Anthropologist on Mars (London 1995)

Shorter, Edward, A History of Psychiatry (New York 1997)

Sobral Cid, José de Matos, Clínica da Perturbações da Memória (1923), in: Obras vol. I (Lisbon 1983):

- Classificação e Sistématica Geral das Psicoses, in: Obras vol. I (1924a)

- A Vida Psíquica dos Esquizofrénicos, in: Obras vol. I (1924b) 
Spangler, Wendy J./G. Rees Cosgrove/H. Thomas Ballantine, Jr/Edwin H. Casem/Scott L. Rauch/Andrew Nierenberg/Bruce H. Price, 'Magnetic resonance image-guided stereotactic cingulotomy for intractable psychiatric disease', Neurosurgery 38 (1996) 1071-1078

Stone, James L. 'Dr Gottlieb Burckhardt - The Pioneer of Psychosurgery', Journal of the History of the Neurosciences 10 (2001) 79-92

Tooth, G. C. /M. P. Newton, 'Leucotomy in England and Wales 1942-1954', Great Britain Ministry of Health Reports on Public Health and Medical Subjects 104 (London 1961)

Torsegno, M. E., ‘La terapia violenta delle psicosi>, Note e riviste di psychiatria 67:5 (1938) 5-44

Valenstein, Eliot S. (ed.), The Psychosurgery Debate. Scientific, Legal and Ethical Perspectives (San Francisco 1980)

- Great and Desperate Cures: the Rise and Decline of Psychosurgery and Other Radical Treatments for Mental Illness (New York 1986)

Whitaker, Harry A./Brigitte Stemmer/Yves Joanette, 'A psychosurgical chapter in the history of cerebral localisation: the six cases of Gottlieb Burckhardt (1891)', in: Code, Chris/Yves Joanette/André Roch Lecours/Claus-W. Wallesch (eds), Classic Cases in Neuropsychology (Hove 1996) 275-303

Windholz, George, 'Pavlov's concept of schizophrenia as related to the theory of higher nervous activity', History of Psychiatry 4 (1993) 511-526

- 'Pavlov's conceptualisation of paranoia within the theory of higher nervous activity', History of Psychiatry 7 (1996) 159-166 